\title{
THERMAL ANALYSIS OF A FLAT-PLATE BOILING COLLECTOR HAVING SUB-COOLED INLET AND SATURATED EXIT STATES
}

\author{
AHMED Y. El-AsSY* and John A. ClaRK' \\ Department of Mechanical Engineering and Applied Mechanics, Solar Energy Laboratory, \\ The University of Michigan, Ann Arbor, Michigan 48109, U.S.A.
}

\begin{abstract}
The analysis of the thermal performance of a boiling flat-plate solar collector is presented. A generalized heat removal factor and a new formulation for the overall thermal loss coefficient are developed. It is demonstrated that the conventional heat removal factor for non-boiling collectors is a limiting case of a more generalized result. The new formulation for the overall thermal loss coefficient is shown to be a function of the fractional non-boiling length of the flow channel. The influence of the inlet sub-cooling is evaluated and the operating limits of solar flat-plate collectors are determined. A comparison is made between the thermal model for boiling collectors having sub-cooled inlet states and experimental results. Favorable agreement is obtained.
\end{abstract}

\section{INTRODUCTION}

The analysis of the thermal performance of flat-plate solar collectors containing a single-phase fluid, developed by Hottel and Woertz[1], and Hottel and Whillier[2], is well established for forced flow systems. Studies of single-phase collector systems operating in a thermosiphon mode have been reported by Shitzer, et al.[3,4], Close[5], Gupta and Garg[6] and Zvirin, et al.[7], among others. Morrison and Braun[8] have summarized both the analytic modeling and the thermal performance of these systems.

Soin, et al.[9] investigated the thermal performance of a thermosiphon collector containing boiling acetone and petroleum ether and correlated their experimental results with a modified form of the HottelWhillier-Bliss equation to account for the fraction of liquid level in the collector. Downing and Waldin[10] studied the boiling heat transfer process in solar water heating using R-11 and R-114. The thermal analysis of a boiling collector has been presented by Al-Tamimi and Clark[11] and the thermal performance of this collector is given by the same authors in [12]. The thermal analysis of the boiling collector has been generalized by Clark[13]. The present paper is a refinement of the theory of the flat-plate boiling collector providing a new formulation of the overall thermal loss coefficient $U_{L}$. The limits of solar radiation at which the boiling collector is incipient to superheated exit conditions are also presented.

\section{COLLECTOR THERMAL PERFORMANCE PARAMETERS}

The thermal conversion efficiency, $\eta$, for solar flatplate collectors is given by

*Permanent address: Department of Mechanical Engineering, Faculty of Engineering, Ain Shams University, Abbassia, Cairo, Egypt.

†Professor Emeritus of Mechanical Engineering and Applied Mechanics. The University of Michigan, Ann Arbor. Member ISES.

$$
\eta=\mathscr{F}_{R}\left[\eta_{o}-\frac{U_{L}\left(T_{1}-T_{a}\right)}{I}\right]
$$

where $\mathscr{F}_{R}$ is the heat removal factor and $U_{L}$ is the overall thermal loss co-efficient, $\eta_{o}$ is the optical efficiency of the cover-absorber plate sub-system derived by standard optical procedures as described in [14], $T_{1}$ and $T_{a}$ are the inlet fluid temperature and the ambient temperature and $I$ is the total incident solar radiation. The overall thermal loss coefficient $U_{L}$ is taken constant along the collector axial length in references [11], [12], and [13]. In the present analysis, however, $U_{L}$ is shown to depend on the fractional non-boiling length, $z^{*}$. Defining the thermal loss coefficient as $U_{N B}$ in the non-boiling region of the collector having sub-cooled inlet conditions and $U_{B}$ in the boiling region, $\mathscr{F}_{R}$ and $U_{L}$ are formulated[15] as

$$
\mathscr{F}_{R}=F_{R}\left[\frac{1-e^{-a z^{*}}}{1-e^{-a}}+\frac{\left(1-z^{*}\right) e^{-a_{b} z^{*}}}{F_{R} / F_{B}^{\prime}}\right]
$$

and

$U_{L}=\frac{\left[\frac{F^{\prime}}{a}\left(1-e^{-a z^{*}}\right)\right] U_{N B}+\left[F_{B}^{\prime}\left(1-z^{*}\right) e^{-a_{b} z^{*}}\right] U_{B}}{\frac{F^{\prime}}{a}\left(1-e^{-a z^{*}}\right)+F_{B}^{\prime}\left(1-z^{*}\right) e^{-a_{b} z^{*}}}$

where $F^{\prime}$ is the collector efficiency factor for the nonboiling region[14] and is defined as

$$
F^{\prime}=\frac{\frac{1}{U_{N B}}}{W\left[\frac{1}{U_{N B}[D+(W-D) F]}+\frac{1}{R_{b}}+\frac{1}{\pi D_{i} h_{l}}\right]}
$$


and the parameter $a$, the dimensionless capacitance rate for non-boiling conditions, is defined as

$$
a=\frac{F^{\prime} U_{N B}}{\left(w / A_{c}\right) c_{p l}}
$$

Here $\omega$ is the coolant mass flow rate, $\mathrm{kg} / \mathrm{s}, A_{c}$ is the collector area, $\mathrm{m}^{2}, z^{*}$ is the ratio of the non-boiling length to the collector axial length and $a_{b}$ is the dimensionless capacitance rate for boiling conditions defined as

$$
a_{b}=\frac{F_{b}^{\prime} U_{B}}{\left(w / A_{c}\right) c_{p l}}=a \frac{F_{b}^{\prime}}{F^{\prime}} \frac{U_{B}}{U_{N B}}
$$

$F_{b}^{\prime}$ is defined as

$$
F_{b}^{\prime}=\frac{\frac{1}{U_{B}}}{W\left[\frac{1}{U_{B}[D+(W-D) F]}+\frac{1}{R_{b}}+\frac{1}{\pi D_{i} h_{l}}\right]}
$$

$F_{B}^{\prime}$ in equations (2) and (3) is the collector efficiency factor for the boiling conditions defined as

$$
F_{B}^{\prime}=\frac{\frac{1}{U_{B}}}{W\left[\frac{1}{U_{B}[D+(W-D) F]}+\frac{1}{R_{b}}+\frac{1}{\pi D_{i} h_{b}}\right]}
$$

and $F_{R}$ in eqn (2) is the heat removal factor for a nonboiling collector having the same value of $a$ and $F^{\prime}$ as the boiling collector with a saturated exit state and is defined [14] as

$$
F_{R}=\frac{F^{\prime}}{a}\left(1-e^{-u}\right)
$$

The complete derivation of eqns (2) and (3) is given in [15].

\section{SATURATED EXIT OPERATION LIMITS}

The limits of operation of a flat-plate collector having saturated exit states are shown in Figure 1. The emphasis in this section is to identify those limits analytically. At small solar flux, especially for large inlet sub-cooling, $T_{\text {sat }}-T_{1}$, boiling will not occur and the collector will operate under single-phase, nonboiling conditions. These states are shown in Fig. 1 as the line $A-A$ for $z^{*}=1.0$. The collector thermal efficiency for non-boiling conditions is obtained from

*Under these circumstances the liquid will be at Tsa with a corresponding pressure $P_{\text {sar }} . T_{\text {sat }}$ (and $P_{\text {sat }}$ ) will vary with operating conditions and application. For solar hot water applications Tsat will be slightly greater than the temperature of the preheat tank. eqns (1) through (3) in which the value of $z^{*}$ in equations (2) and (3) is unity. Another limiting case is that for saturated liquid inlet conditions. ${ }^{*}$ Since the fluid enters the collector channels as a saturated liquid boiling occurs from the collector inlet. The entire collector length is then under boiling conditions. This is the fully boiling condition shown in Figure 1 by the line $F-F$. For these states there will be a limiting value of the solar flux. $I \dagger$, at which the fluid quality $\dagger$ at the collector exit is unity and the fluid at the exit is in an incipient superheated state. This is expressed as follows from a thermal analysis of the channel flow

$$
w h_{f g}=F_{B}^{\prime} A_{\mathrm{c}}\left[I \dagger \eta_{o}-U_{B}\left(T_{\mathrm{sat}}-T_{a}\right)\right]
$$

Rearranging and introducing eqn (5), eqn (10) is rewritten as

$$
\digamma=\frac{h_{f g} U_{\mathrm{V} B}}{a\left(F_{B}^{\prime} / F^{\prime}\right) c_{\rho l} \eta_{o}}+\frac{U_{B}\left(T_{\mathrm{sat}}-T_{a}\right)}{\eta_{o}}
$$

Introducing a new dimensionless boiling capacitance rate. $a_{B}$, defined as

$$
a_{B}=a \frac{F_{B}^{\prime}}{F^{\prime}} \frac{U_{B}}{U_{V B}}
$$

the critical solar flux, $I^{\dagger}$, for saturated vapor exit state is

$$
I \dagger=\frac{U_{B}\left(T_{\mathrm{sat}}-T_{a}\right)}{\eta_{o}}\left[1+\frac{1}{a_{B}} \frac{h_{f s}}{c_{p l}\left(T_{\mathrm{sat}}-T_{a}\right)}\right]
$$

The thermal efficiency corresponding to the solar flux $I \dagger$ determines the upper limit of the efficiency for the fully boiling condition. The lower limit of the efficiency for the fully boiling condition is the intersection of the limit $F-F$ with the fully non-boiling line $A-A$, Fig. 1. The reduced temperature at which this intersection takes place is designated as

$$
\left(\frac{\Delta T}{I}\right)^{*}
$$

and is derived as follows. For the fully non-boiling conditions, that is, at $z^{*}=1.0, F_{R}$ becomes $F_{R}$, equation (2). For the fully boiling conditions, that is, at $z^{*}=0.0, F_{R}$ is $F_{B}^{\prime}$. Since the value of the efficiency at the intersection of the limits $F-F$ and $A-A$ is identical for the conditions of $z^{*}=1.0$ and $z^{*}=$ 0.0 , it is clear that

$$
\begin{aligned}
& F_{R}\left[\eta_{o}-U_{N B}\left(\frac{\Delta T}{I}\right)^{*}\right] \\
& =F_{B}^{\prime}\left[\eta_{o}-U_{B}\left(\frac{\Delta T}{I}\right)^{*}\right]
\end{aligned}
$$

\footnotetext{
$\doteqdot$ Also known as dryness fraction or vapor mass fraction.
} 


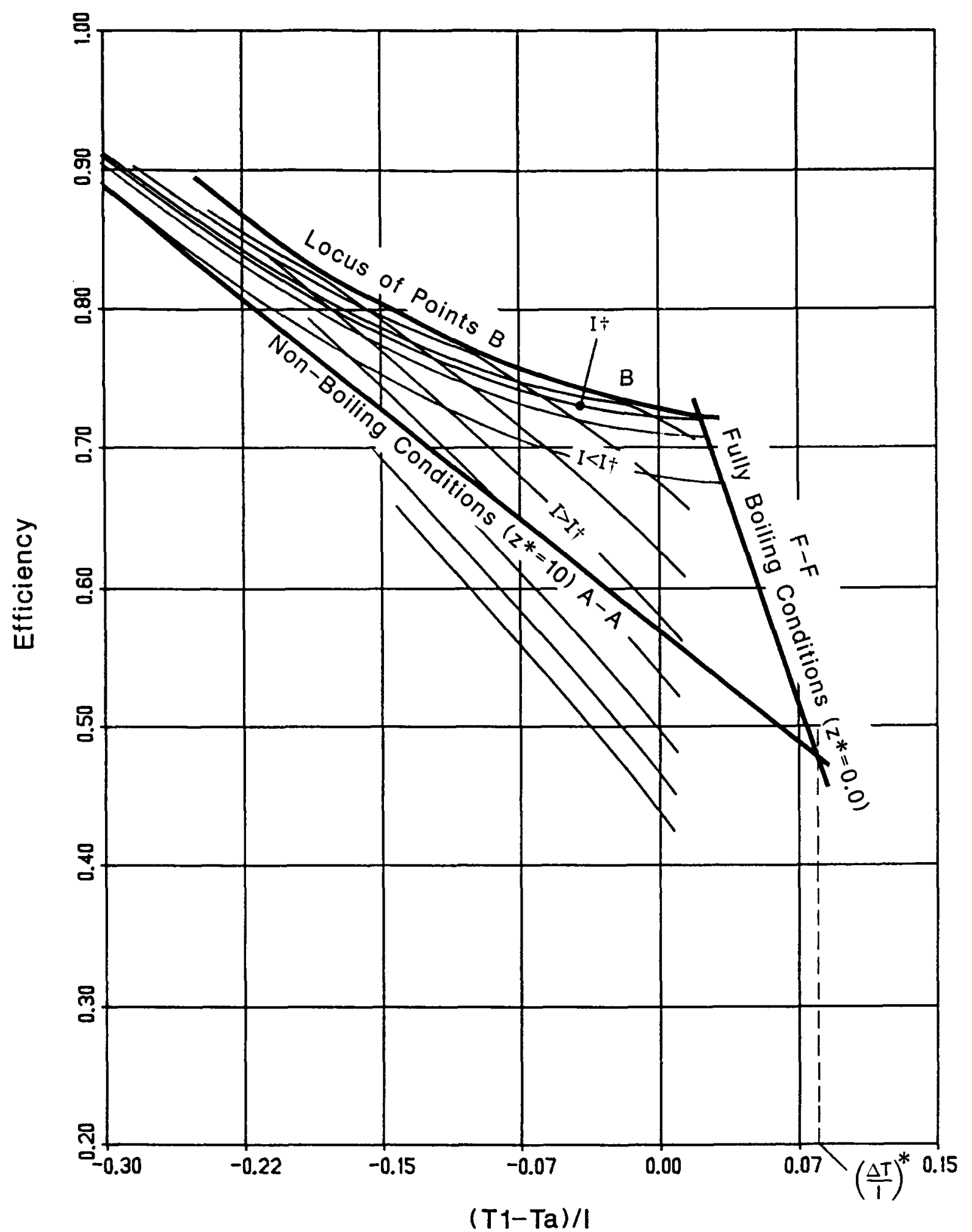

Fig. 1. Operational limits of flat-plate collectors. 
Hence, the reduced temperature becomes

$$
\left(\frac{\Delta T}{I}\right)^{*}=\frac{\eta_{o}}{U_{N B}} \frac{\left[1-F_{B}^{\prime} / F_{R}\right]}{\left[1-a_{B} /\left(1-e^{-a}\right)\right]}
$$

If the solar radiation intensity is greater than $1 \dagger$, superheated exit states will occur[15]. Because boiling conditions enhance the collector thermal performance by increasing its efficiency compared to the non-boiling conditions efficiency at the same coolant flow rate $([11],[12]$, and [13]) and because superheating increases the thermal losses, thus decreasing the collector efficiency[15], there exist a point for each $I>I \dagger$ at which the collector efficiency has a deflection point (point B in Fig. 1). Each point B is actually the collector operating conditions at which the exit fluid is in an incipient for superheated exit state. The locus of points B is, therefore, the upper limit of operation for saturated exit states. Using eqn (10) and recognizing that, in general, the collector area needed to provide an amount of useful energy equal to $w h_{f g}$ is $A_{c}\left(1-z^{*}\right)$ eqn (10) is written as

$$
w h_{f g}=F_{B}^{\prime} A_{c}\left(1-z^{*}\right)\left[l \eta_{o}-U_{B}\left(T_{\mathrm{sat}}-T_{\mathrm{d}}\right)\right]
$$

Also it is shown[15] that

$$
\frac{I \eta_{o}-U_{B}\left(T_{\mathrm{sat}}-T_{a}\right)}{I \eta_{o}-U_{B}\left(T_{1}-T_{a}\right)}=e^{-a_{b} z^{*}}
$$

Substituting eqn (17) into (16) and rearranging, the locus of points $B$ is determined by

$$
\frac{T_{1}-T_{a}}{I}=\frac{\eta_{0}}{U_{B}}-\frac{h_{f k}}{I a_{B}\left(1-z^{*}\right) c_{p l} e^{-a_{b}=*}}
$$

The fractional non-boiling length, $z^{*}$, is calculated[11], [12] and [13] as

$$
z^{*}=\frac{1}{a} \ln \frac{\eta_{o}-U_{N B} \frac{T_{1}-T_{a}}{I}}{\eta_{o}-U_{N B} \frac{T_{\mathrm{SAT}}-T_{a}}{I}}
$$

\section{RESULTS AND DISCUSSION}

The boiling flow factor $F_{B}^{\prime \prime}$ is defined as

$$
F_{B}^{\prime \prime}=\frac{F_{R}}{F_{B}^{\prime}}
$$

The effect of the dimensionless non-boiling length $z^{*}$ on the boiling flow factor is shown in Figs. 2 and 3 for $F_{B}^{\prime} / F^{\prime}=1.00$ and 1.10 , respectively. The lower limit of $F_{B}^{\prime \prime}$ is the traditional flow factor $F^{\prime \prime}[14]$ and corresponds to the fully non-boiling condition, that is, $z^{*}=1.0$. The upper limit of $F_{B}^{\prime \prime}$ is unity, its maximum possible value, and corresponds to the fully boiling conditions, $z^{*}=0.0$. Comparing values of $F_{B}^{\prime \prime}$ in Figs. 2 and 3 at the same $1 / a$. it is seen that the value of the flow factor $F_{B}^{\prime \prime}$ is increased as the ratio $F_{B}^{\prime} / F^{\prime}$ is decreased. The function $F_{B}^{\prime \prime}$ reaches its maximum value, independent of the value of $1 / a$, when the ratio $F_{B}^{\prime} / F^{\prime}$ is unity. This indicates that the thermal performance of flat-plate collectors is enhanced when boiling conditions occur, a conclusion consistent with the fact that the boiling flow factor $F_{B}^{\prime \prime}$ increases, for a fixed $F_{B}^{\prime} / F^{\prime}$ ratio, as $z^{*}$ decreases.

Some additional insights into the performance of boiling collectors in comparison with non-boiling collectors is also provided by the asymptotic limit analysis in which $a=0$ or $a^{-1}=x$. For this case $\mathscr{F}_{R}$ is written as

$$
F_{R}=F^{\prime}\left[z^{*}+\frac{F_{B}^{\prime}}{F^{\prime}}\left(1-z^{*}\right)\right]
$$

and the boiling flow factor $F_{B}^{\prime \prime}$ becomes

$$
F_{B}^{\prime \prime}=1-z^{*}\left(1-\frac{F^{\prime}}{F_{B}^{\prime}}\right)
$$

Equation (22) shows explicitly that, for a constant value of $z^{*}, F_{B}^{\prime \prime}$ increases as $F_{B}^{\prime} / F^{\prime}$ decreases as shown by comparing Fig. 2 to Fig. 3. For $F_{B}^{\prime} / F^{\prime}=1.0$, the asymptotic value of $F_{B}^{\prime \prime}$ is unity which represents the case of a fluid of infinitely large thermal capacity flowing through the collector.

Figures 4 through 7 show the flat-plate thermal efficiency as a function of the reduced temperature $\left(T_{1}-T_{a}\right) / l$ at various solar fluxes for different coolant mass flow rates and working pressures. Figure 4 shows the collector thermal performance for R-11 mass flow rate per unit collector area, $w / A_{c}=0.002 \mathrm{~kg} /$ $\mathrm{sm}^{2}$ working at a pressure of $0.32 \mathrm{MPa}\left(T_{\text {sat }}=60^{\circ} \mathrm{C}\right)$. For the collector characteristic parameters used in the simulation, $F^{\prime}$ is 0.958 and $U_{\mathrm{xB}}$ is $3.5 \mathrm{~W} / \mathrm{m}^{2} \mathrm{~K}$. The dimensionless capacitance rate, $a$, eqn (5), is 1.8 . For these conditions, $I \dagger$, defined by equation (13). is equal to $607 \mathrm{~W} / \mathrm{m}^{2}$. At solar fluxes smaller than $I \uparrow$, the exit fluid states are always saturated (except for fully non-boiling conditions, $z^{*}=1.0$ ) with exit quality, $x_{e}$, less than unity. This is also the case $\left(x_{e}\right.$ < 1) at a solar flux of $I \dagger \mathrm{W} / \mathrm{m}^{2}$ but with inlet fluid temperature $T_{1}$ less than $T_{\text {sat }}$. At $I=I^{\dagger}$ and $T_{1}=T_{\text {sar }}$, the exit quality is exactly unity, $x_{e}=1.0$. For solar fluxes greater than $I \dagger$, the fluid exit quality is unity at points $\mathbf{B}$, which reduced temperatures are determined by eqn (18). At greater reduced temperatures than those determined by eqn (18), the fluid exit states are superheated conditions (superheated exit states are shown in Figs. 4 through 7 by dashed lines). 


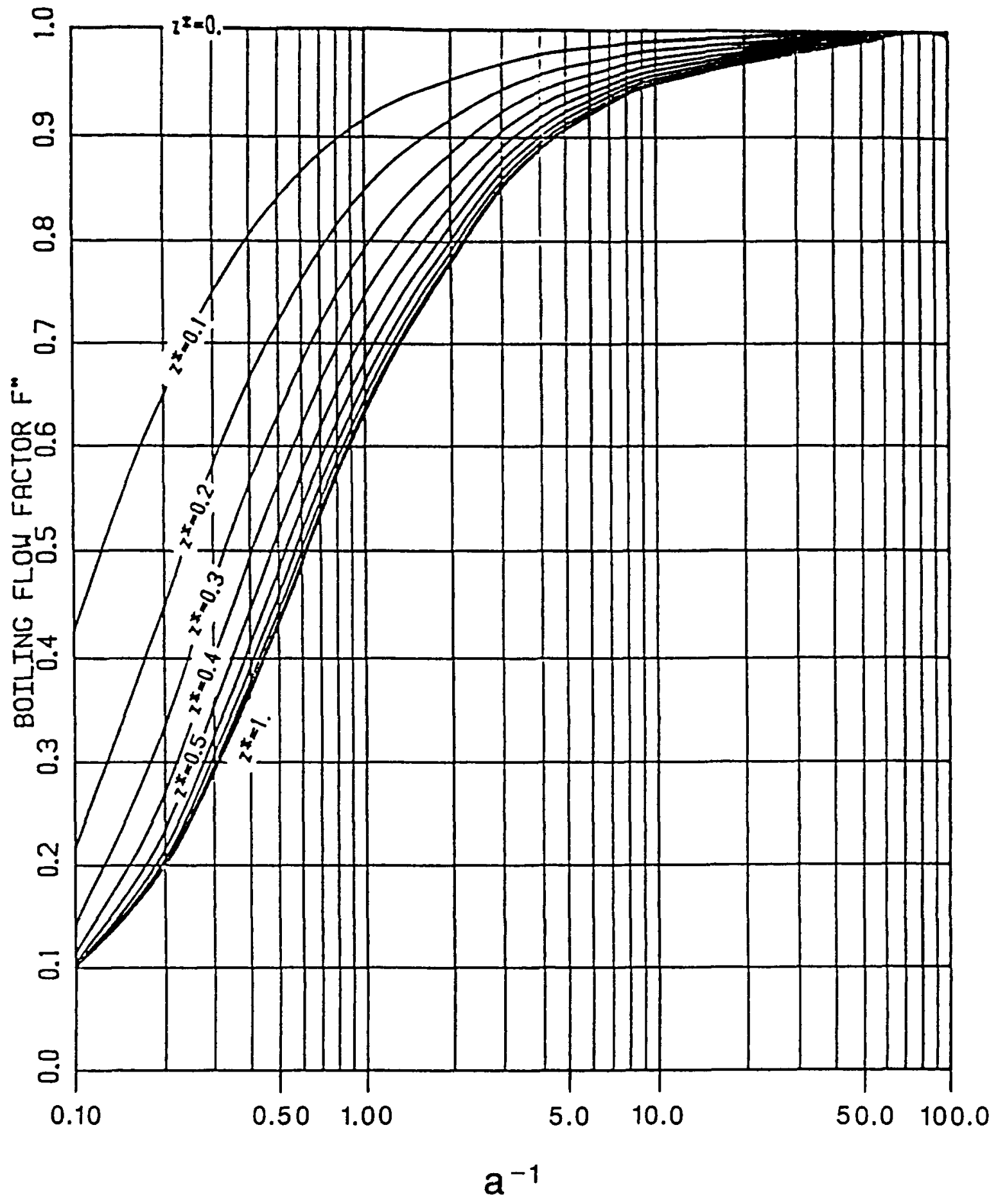

Fig. 2. Boiling flow factor $F_{B}^{\prime \prime}=F_{R} / F_{B}^{\prime}$ for $F_{B}^{\prime} / F^{\prime}=1.00$

Figure 5 shows the collector thermal efficiency for an R-11 mass flow rate per unit collector area of 0.002 $\mathrm{kg} / \mathrm{sm}^{2}$ at a working pressure of $0.12 \mathrm{MPa}\left(T_{\text {sat }}=\right.$ $\left.30^{\circ} \mathrm{C}\right)$. The parameter $a$, eqn $(5)$, is taken to be the same, $a=1.8$, as for the conditions represented by Fig. 4 so that the comparison between Fig. 4 and Fig. 5 reflects only the effect of the working pressure (or the saturation temperature, $T_{\text {sat }}$ ) on the collector performance. Comparing collector efficiencies at the same $I$ and $\left(T_{1}-T_{a}\right) / I$ in Figs. 4 and 5 , the thermal efficiencies for $T_{\text {sat }}=30^{\circ} \mathrm{C}$ (Fig. 5) are greater than those for $T_{\text {sat }}=60^{\circ} \mathrm{C}$ (Fig. 4) as the fluid temperature is lower and hence thermal losses are smaller. For $T_{\text {sat }}$ of $30^{\circ} \mathrm{C}$ the value of $I \div$ is $457 \mathrm{~W} / \mathrm{m}^{2}$ which is 


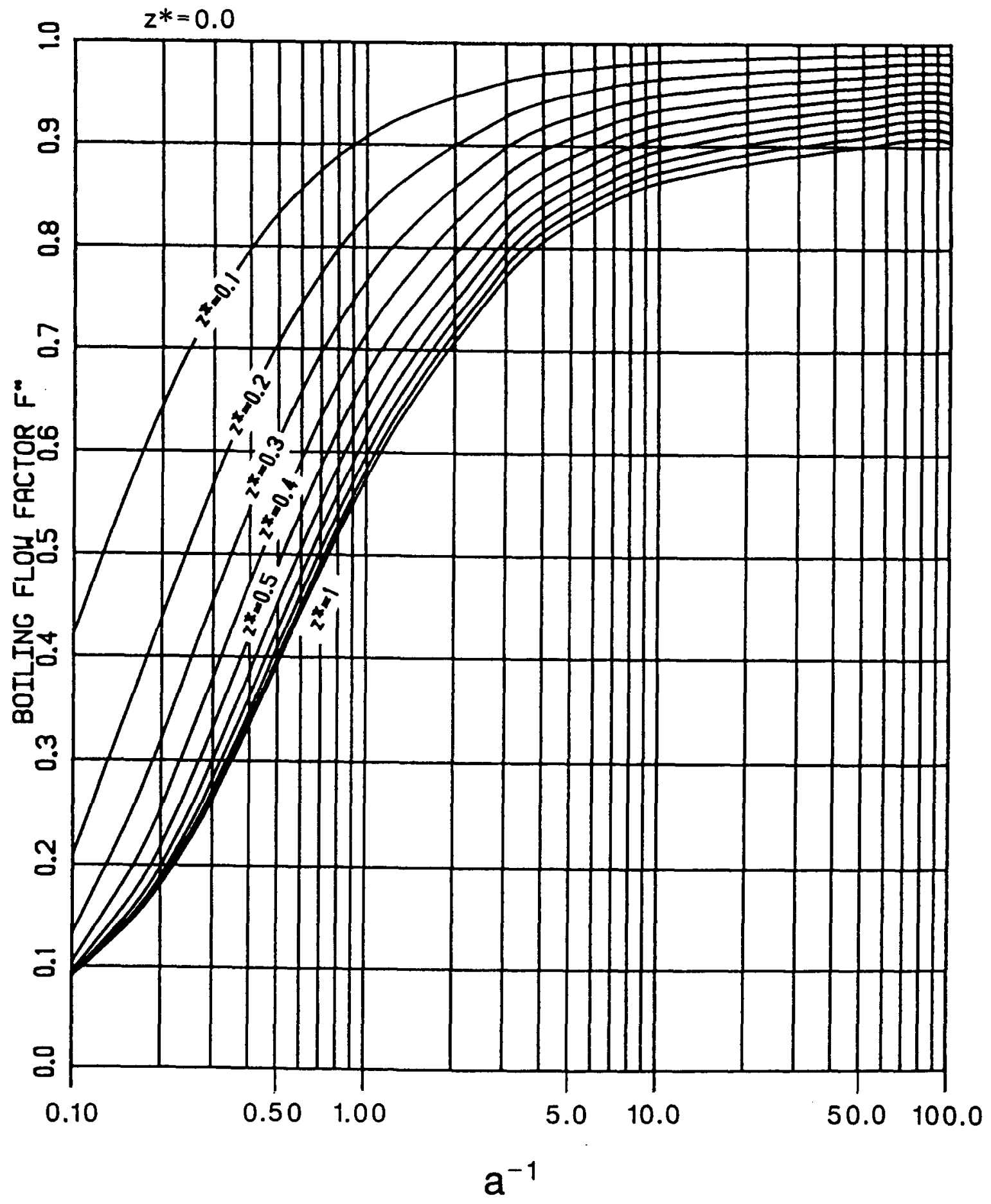

Fig. 3. Boiling flow factor $F_{B}^{\prime \prime}=F R / F_{B}^{\prime}$ for $F_{B}^{\prime} / F^{\prime}=1.10$

less than the value of $I \dagger$ for a $T_{\text {sat }}$ of $60^{\circ} \mathrm{C}(607 \mathrm{~W} /$ $\mathrm{m}^{2}$ ), as evident from eqn (13).

The collector thermal efficiency for $T_{\text {sat }}$ equal to 60 and $30^{\circ} \mathrm{C}$, respectively, and an R-11 mass flow rate per unit collector area, $w / A_{c}$, of $0.004 \mathrm{~kg} / \mathrm{sm}^{2}$ is given in Figs. 6 and 7. Increasing the coolant mass flow rate through the collector subsequently increases the values of $1 / a$, eqn (5), $1 / a_{b}$, eqn (6) and $1 / a_{B}$, eqns (12). For $w / A_{c}=0.004 \mathrm{~kg} / \mathrm{sm}^{2}, U_{v B}$ is equal to $2.5 \mathrm{~W} / \mathrm{m}^{2} \mathrm{~K}$ and $a=0.65$. The value of the boiling flow factor $F_{B}^{\prime \prime}$ increases as the coolant mass flow rate increases. The effect of increasing the mass flow rate on the thermal efficiency is determined by comparing the results in Figures 4 and 6 at a specific solar flux (at $T_{\text {sat }}=60^{\circ} \mathrm{C}$ ) and in Figs. 5 and 7 (at $T_{\text {sat }}=30^{\circ} \mathrm{C}$ ). As can be seen the thermal efficiency increases as 


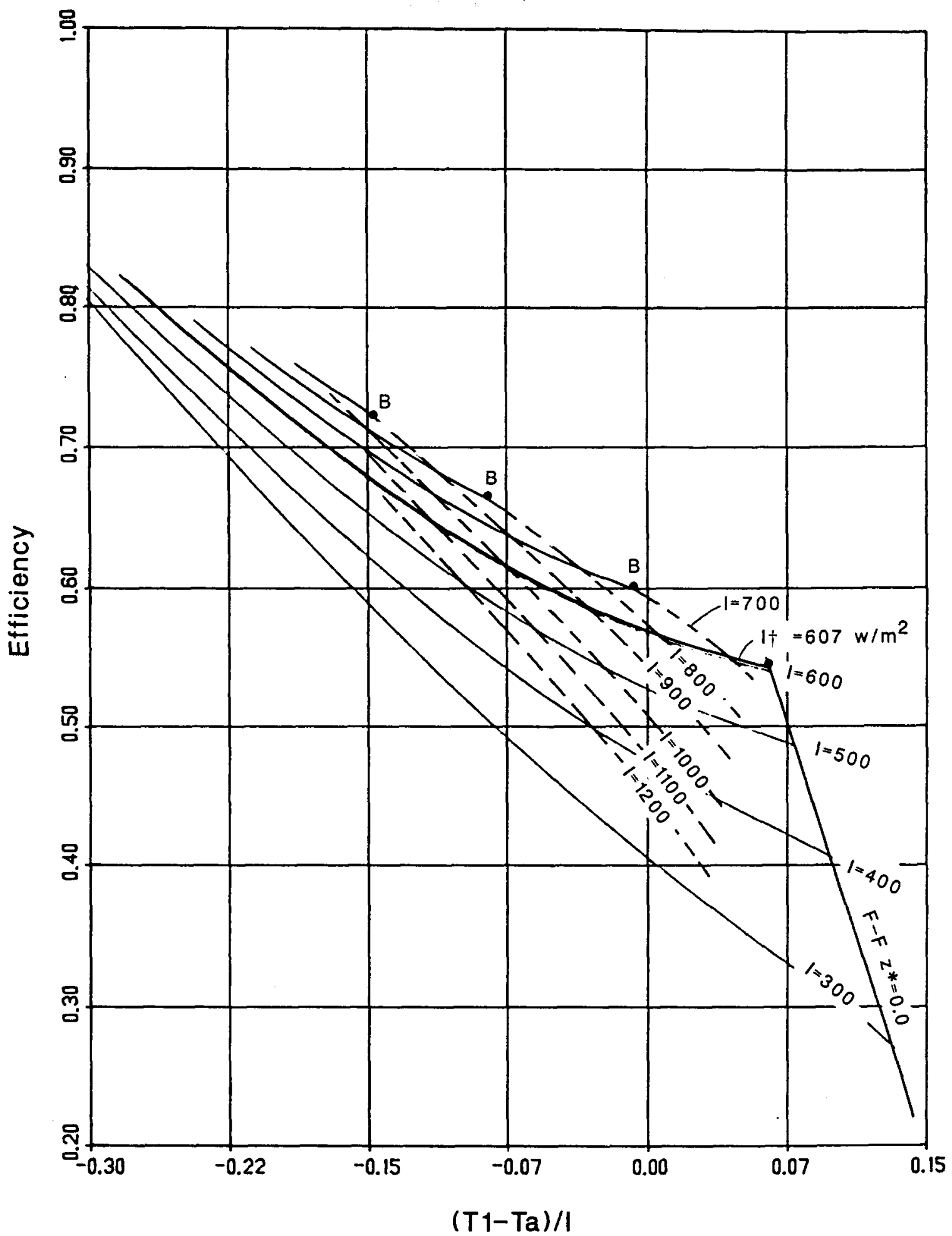

Fig. 4. Thermal efficiency, $\eta$, at $T_{\mathrm{sat}}=60^{\circ} \mathrm{C}$ and $a=1.8$

the mass flow rate is increased, other conditions being fixed. It may also be seen that $I \dagger$ is increased as the mass flow rate increases.

Experimental data were obtained by Al-Tamimi and Clark[11] and [12] for a flat-plate boiling col- lector, using R-11, in a thermosiphon loop. Because of the characteristics of the thermosiphon loop, the coolant mass flow rate is dependent on the intensity of the solar flux, as illustrated in reference [11]. The collector parameters, as determined from the exper- 


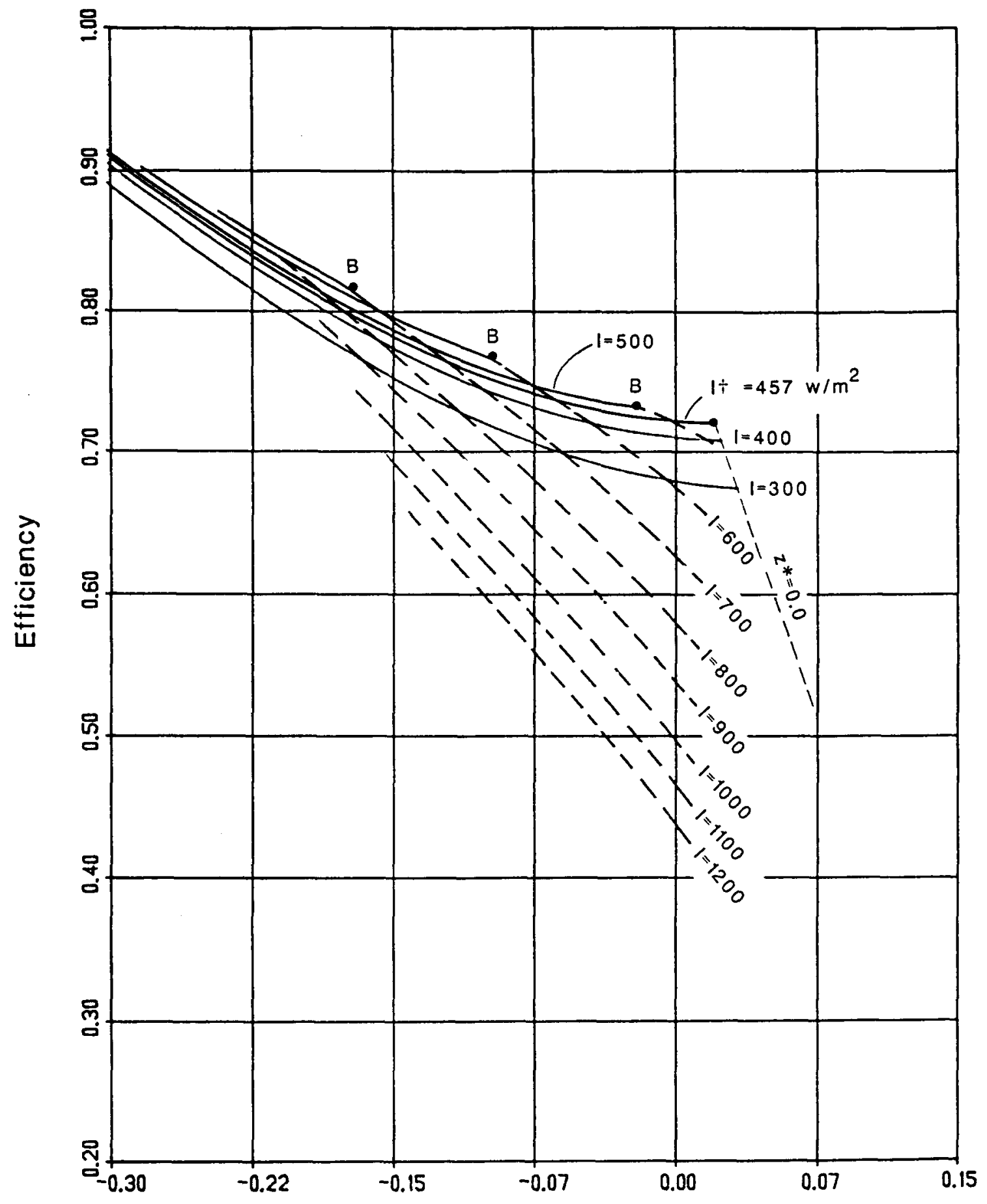

$(\mathrm{T} 1-\mathrm{Ta}) / 1$

Fig. 5. Thermal efficiency, $\eta$, at $T_{\text {sat }}=30^{\circ} \mathrm{C}$ and $a=1.8$

iments ([11] and [12]), are used as input for the present model. The results of the simulation are shown in Fig. 8 as the solid curves. The experimental data points are also shown in Fig. 8. The comparison of the results of the present model and the experimental data by Al-Tamimi and Clark is seen to be satisfactory. The experimental $l^{\dagger}$ value $[11]$ is $962 \mathrm{~W} / \mathrm{m}^{2}$ (taken from [11] as maximum $I$ at $z^{*}=0.0$ ). This quantity in the present model, as calculated from eqn (13), is equal to $887 \mathrm{~W} / \mathrm{m}^{2}$. Hence, the agreement 


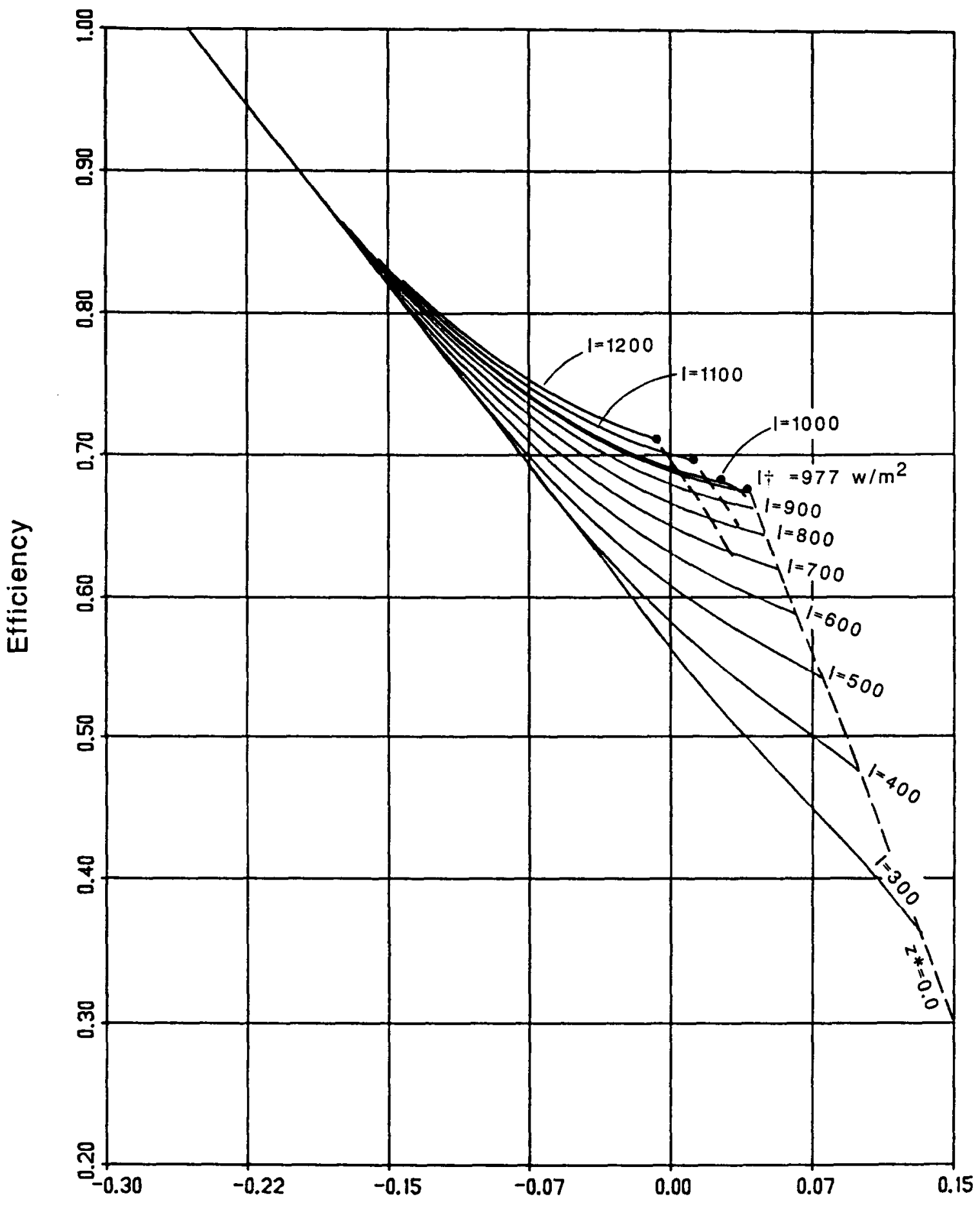

$(\mathrm{T} 1-\mathrm{Ta}) / /$

Fig. 6. Thermal efficiency, $\eta$, at $T_{\mathrm{sat}}=60^{\circ} \mathrm{C}$ and $a=0.65$

between the $1 \dagger$ experimental and theoretical values is within $7.8 \%$. The difference between the $I \dagger$ experimental and theoretical values is within the experimental uncertainty involved in the measurement of the fractional non-boiling length, $z^{*}$, and the deter- mination of the other parameters, such as $a, I, w$, etc., which govern the thermal performance of the collector[11]. There is some possibility that the exit conditions for this particular experimental point $(I=$ $962 \mathrm{~S} / \mathrm{m}^{2}$ ) were slightly superheated, something the 


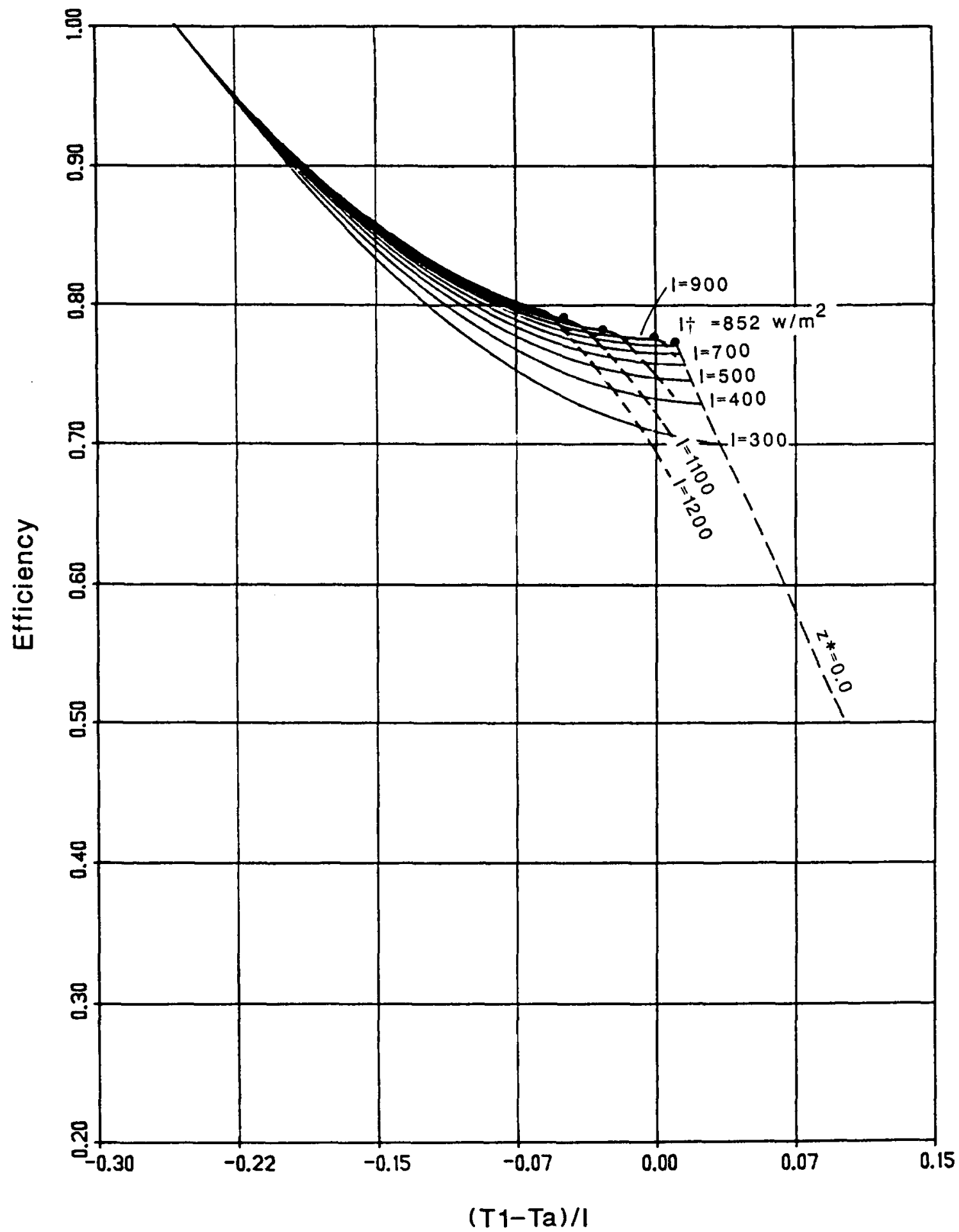

Fig. 7. Thermal efficiency, $\eta$, at $T_{\text {sat }}=30^{\circ} \mathrm{C}$ and $a=0.65$

measuring system was unable to confirm. Should this be the case the comparison with the theory would be even better as the experimental point for $I=962 \mathrm{~W} /$ $\mathrm{m}^{2}$ (Fig. 8) falls slightly below the theoretical line $\left(I \dagger=887 \mathrm{~W} / \mathrm{m}^{2}\right)$ which would be the case for a collector having a superheated exit state.

\section{CONCLUSION}

A generalized model for boiling flat-plate collectors is presented which illustrates the operational limits for collector operation having saturated fluid exit states and sub-cooled inlet states. The new general- 


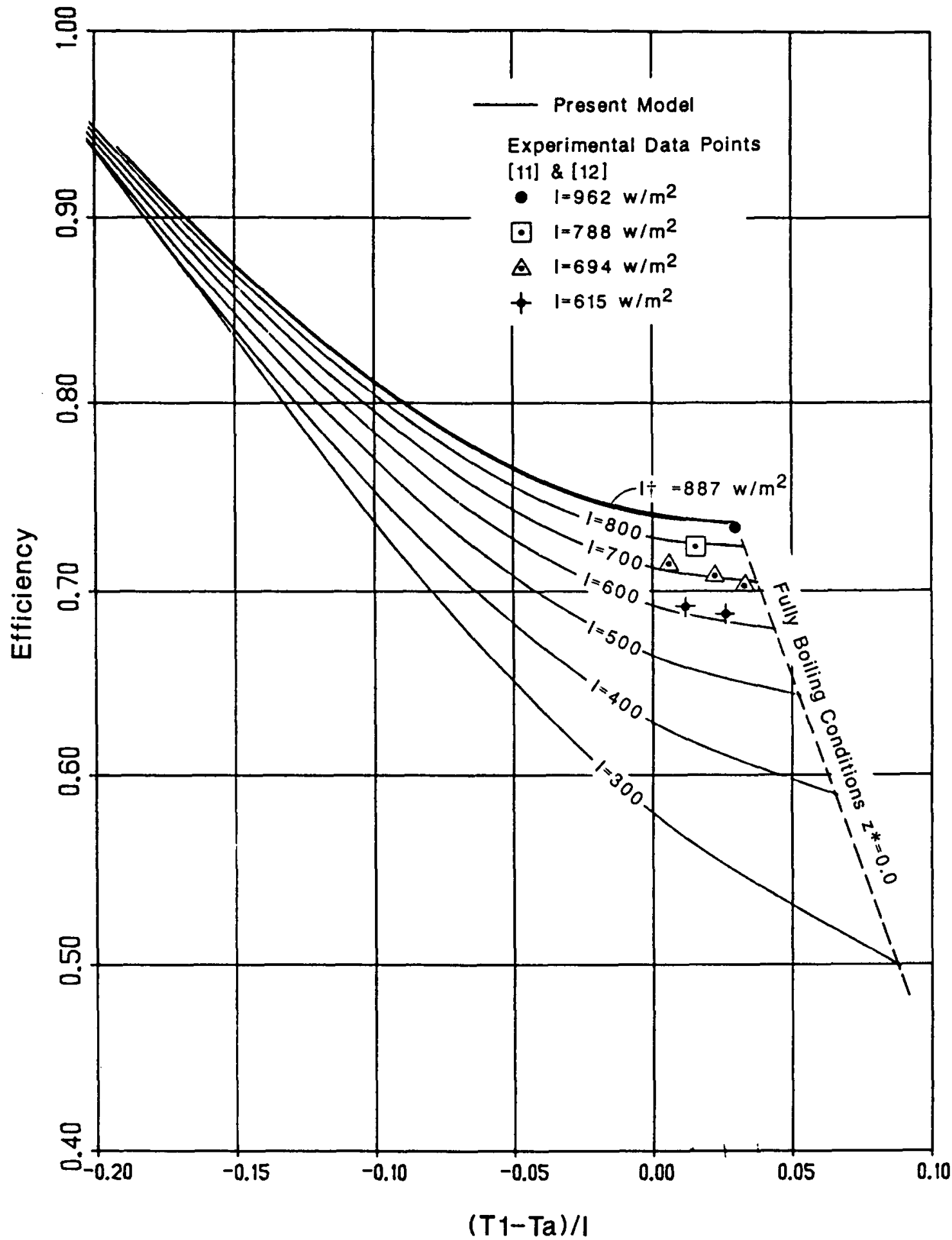

Fig. 8. Comparison with experimental data from $[11,12]$

ized heat removal factor and the new overall thermal loss coefficient developed by the authors in an earlier study[15] are applied in the present work for saturated exit conditions. Results of the theoretical simulation are in satisfactory agreement with the experimental data from a flat-plate boiling collector reported by Al-Tamimi and Clark ([11] and [12]) which operated with sub-cooled inlet conditions and saturated exit conditions.

\section{NOMENCLATURE}

a Capacitance rate (non-boiling) eqn (5) [1]

$a_{b}$ Capacitance rate (non-boiling) eqn (6) [1] 
$u_{B}$ Capacitance rate (boiling) eqn (12) [1]

$A_{c}$ Collector area $\left[\mathrm{m}^{2}\right]$

$C_{p i}$ Heat capacity liquid $[\mathrm{J} / \mathrm{kgK}]$

$D$ Tube diameter $[\mathrm{m}]$

$F^{\prime}$ Collector efficiency factor (non-boiling) eqn (4) [1]

$F_{R}$ Heat removal factor (non-boiling) eqn (9) [1]

$F_{b}^{\prime}$ Collector efficiency factor (boiling) eqn (7) [1]

$F_{B}^{\prime}$ Collector efficiency factor (boiling) eqn (8) [1]

$\mathscr{F}_{R}$ Heat removal factor (boiling) eqn (2) [1]

$F_{B}^{\prime \prime}$ Boiling flow factor, eqn (20) [1]

$F$ Fin efficiency [1]

$h_{t}$ Liquid heat transfer coefficient $\left[W / \mathrm{m}^{2} \mathrm{~K}\right]$

$h_{b}$ Boiling heat transfer coefficient $\left[\mathrm{W} / \mathrm{m}^{2} \mathrm{~K}\right]$

$h_{f g}$ Latent heat of vaporization $[J / \mathrm{kg}]$

$l$ Incident solar flux $\left[\mathrm{W} / \mathrm{m}^{2}\right]$

It Limiting-valve, solar flux, eqn(11) $\left[\mathrm{W} / \mathrm{m}^{2}\right]$

$L_{N B} \quad$ Non-boiling channel length [m]

$L$ Channel length $[\mathrm{m}]$

$P_{\text {SAT }}$ Saturation pressure of coolant $\left[N / \mathrm{m}^{2}\right]$

$\boldsymbol{R}_{b}$ Thermal resistance of bond $[\mathrm{W} / \mathrm{mK}]$

$T_{1}$ Coolant inlet temperature [K]

$T_{a}$ Ambient temperature $[\mathrm{K}]$

$T_{\mathrm{SAT}}$ Saturation temperature of coolant [K]

$U_{L}$ Overall loss coefficient (total) $\left[\mathrm{W} / \mathrm{m}^{2} \mathrm{~K}\right]$

$U_{N B}$ Overall loss coefficient (non-boiling) $\left[\mathrm{W} / \mathrm{m}^{2} \mathrm{~K}\right]$

$U_{\theta}$ Overall loss coefficient (boiling) $\left[W / \mathrm{m}^{2} \mathrm{~K}\right]$

$w$ Coolant flow rate $[\mathrm{kg} / \mathrm{s}]$

$W$ Tube spacing $[\mathrm{kg} / \mathrm{s}]$

$Z^{*} \quad L_{N B} / L$ dimensionless non-boiling length [1]

$\eta$ Collector efficiency [1]

$\eta_{0}$ Optical efficiency of cover-absorber system [1]

Acknowledgment-The authors wish to acknowledge the interest and helpful support in this research by $\mathrm{Mr}$. Edward W. Bottum. President, Refrigeration Research Inc., Solar Research Division. Brighton, Michigan, USA.

\section{REFERENCES}

1. H. C. Hottel, and B. B. Woertz, Performance of flat plate solar-heat collectors. Trans. ASME 64, 91 (1942).

2. H. C. Hottel, and A. Whiltier, Evaluation of flat-plate solar collector performance. Trans. of the conference on the use of solar energy 74-104, University of Arizona (1955).

3. A. Shitzer. D. Kalmanoviz. Y. Zvirin, and G. Grossman, Experiments with a flat-plate solar water heating system in thermosiphonic flow. Solar Energy 22, 27 (1979).

4. G. Grossman. A. Shitzer, and Y. Zvirin. Heat transfer analysis of a flat-plate solar energy collector. Solar Energy 19, 493 (1977).

5. D. J. Close. The performance of solar water heaters with natural circulation. Solar Energy 6, 33 (1962).

6. C. L. Gupta, and H. P. Garg, System design in solar water heaters with natural circulation. Solar Energy 12, 163 (1968).

7. Y. Zvirin, A. Shitzer, and G. Grossman, The natural solar heater models with linear and non-linear temperature distributions. Int. J. Heat Mass Transfer 20, 997 (1977).

8. G. L. Morrison, and J. E. Braun, System modeling and operation characteristics of thermopsyphon solar water heaters. Solar Energy 34, 4 (1985).

9. R. S. Soin. K. Sangameswar, D. P. Rao, and K. S. Rao. Performance of tlat-plate solar collector with fluid undergoing phase change. Solar Energy 23, 69 (1979).

10. R. C. Downing, and V.W. Waldin, Phase-change heat transfer in solar hot water heating using R-11 and R14. ASHRAE Trans. 86, part 1 (1980).

11. A. I. Al-Tamimi, and J. A. Clark, Thermal analysis of a solar collector containing a boiling fluid. Proceedings. American Solar Energy Society annual meeting, Minneapolis, MN. June 1-3 (1983).

12. A. I. Al-Tamimi, and J. A. Clark, Thermal performance of a solar collector containing a boiling fluid. AT-84-13. No 1, ASHRAE Symposium on Boiling Collectors. Atlanta, GA. January (1984).

13. J. A. Clark. Analysis of the thermal performance of boiling collectors. Current Research in Heat and Mass Transfer, Proceedings of the Eighth National Heat and Mass Transfer conference, India (1985).

14. J. A. Duffie, and W. A. Beckman. Solar engineering of thermal processes. John Wiley and Sons Inc., NY (1980).

15. A.Y. El-Assy, and J.A. Clark, Thermal analysis of a flat-plate collector in multi-phase flows, including exit superheat. Solar Energy 40, 4 (1988). 